\title{
COVID-19 and Higher Education: First-Year Students' Expectations toward Distance Learning
}

\author{
Karina Cicha ${ }^{1}$, Mariia Rizun ${ }^{2}\left(\mathbb{D}\right.$, Paulina Rutecka ${ }^{2}$ and Artur Strzelecki ${ }^{2, * \mathbb{D}}$ \\ 1 Department of Communication Design and Analysis, University of Economics in Katowice, 40-287 Katowice, \\ Poland; karina.cicha@ue.katowice.pl \\ 2 Department of Informatics, University of Economics in Katowice, 40-287 Katowice, Poland; \\ mariia.rizun@ue.katowice.pl (M.R.); paulina.rutecka@ue.katowice.pl (P.R.) \\ * Correspondence: artur.strzelecki@ue.katowice.pl
}

Citation: Cicha, K.; Rizun, M.; Rutecka, P.; Strzelecki, A. COVID-19 and Higher Education: First-Year Students' Expectations toward Distance Learning. Sustainability 2021, 13, 1889. https://doi.org/10.3390/ su13041889

Academic Editor: Santiago Tejedor Calvo

Received: 20 December 2020

Accepted: 5 February 2021

Published: 9 February 2021

Publisher's Note: MDPI stays neutral with regard to jurisdictional claims in published maps and institutional affiliations.

Copyright: (c) 2021 by the authors. Licensee MDPI, Basel, Switzerland. This article is an open access article distributed under the terms and conditions of the Creative Commons Attribution (CC BY) license (https:/ / creativecommons.org/licenses/by/ $4.0 /)$.

\begin{abstract}
The article deals with distance education, which as a teaching method had to be suddenly introduced in schools and higher education institutions as a result of the global pandemic situation. The paper captures the second wave of Poland's pandemic situation in relation to global circumstances and the methods of conducting distance learning used across the globe. The purpose of this study was to investigate first-year students' expectations about the education shift to distance learning. GETAMEL, which is the adapted General Extended Technology Acceptance Model for E-Learning, was used in the study. The study analyzed the influence of Experience, Subjective Norms, Enjoyment, Computer Anxiety, and Self-Efficacy on students' expectations in the context of distance learning during the COVID-19 pandemic. To test the research model presented during the research, The Partial Least Squares method of Structural Equation Modeling was used. An online survey was created to conduct the research, which collected data from 670 Polish first-year undergraduate students. The acquired data were analyzed using the SmartPLS 3 software. The results of the research indicated that the most important factors that influence the feelings of students and can convince them to change from teaching in the classroom to teaching in the distance learning model are the feeling of pleasure in this form of education and a sense of self-efficacy. The results of this study may be of particular interest to education practitioners, including teachers, and a starting point for further research on e-learning models, including, in particular, the understanding of students' expectations regarding distance learning.
\end{abstract}

Keywords: e-learning; distance learning; higher education; COVID-19; coronavirus; pandemic; first-year students; expectations; attitude; technology acceptance

\section{Introduction}

The COVID-19 pandemic, whose outbreak took place in March 2020, has changed human lives worldwide both directly and indirectly. Governments have decided to shift many everyday activities, such as work or education, online to prevent the spreading of the virus [1]. Some daily practices, like traveling or going outside, were banned for a while. Since the first reports confirming cases of $2019-\mathrm{nCoV}$ and deaths caused by the virus, a year has passed [2]. The main question now is not how long the pandemic will last, but rather what impact it will have on the everyday lives of thousands of people around the world, and whether this impact will be permanent [3].

One of the fields touched by the COVID-19 pandemic is higher education. The shift to distance learning after the pandemic outbreak is a globally observable fact. Although some of the schools, as well as the universities, used remote learning before the pandemic, it was not obligatory and did not focus on the whole teaching process. After the outbreak of the COVID-19 pandemic, universities and schools around the world were shut down and the distance learning for every subject or course has become a daily practice. This change forced both teachers and students to adapt to a new reality, despite the problems 
both of them experienced. Furthermore, it was also an organizational challenge in terms of conducting the whole teaching process for the universities worldwide.

\subsection{Teaching Policies during the Pandemic in Selected Countries Worldwide}

The shift to distance learning after the pandemic outbreak is a globally observable fact. This change forced both teachers and students to adapt to a new reality. Furthermore, it was also an organizational challenge in terms of conducting the whole teaching process.

Teaching policies during the pandemic have been broadly discussed in many countries. In Germany, $90 \%$ of schools are public [2] and, in order to conduct classes, they need to fulfill governmental outlines for dealing with the pandemic. Before the pandemic outbreak, distance learning was broadly discussed, while in higher education, online teaching has been used for more than 20 years [4,5]. However, the shift in the teaching process has been forced by the circumstances. Researchers noted that many teachers developed their digital competencies, in Germany and other countries [4]. It was motivated and even forced by the existing situation. However, it is not known whether, after the end of the COVID-19 crisis, they will continue to use new skills, develop digital teaching methods and tools [6], or return to classic teaching methods in direct contact with students.

The experience of online teaching in China revealed problems of practical nature. Soon after the pandemic outbreak, distance learning was organized. It was observed in the first stage of the process that, despite government efforts, there were many difficulties in distance learning. The infrastructure for online teaching was either missing or insufficient. Teachers had no experience of working this way, and this lack of experience had an impact on the quality of education. The problem of distance learning was also influenced by the lack of clear information and the complexity of the work and study environment at home [6].

Nevertheless, what has been pointed out is that the Chinese government provided the teachers with extra training in using online tools, along with local authorities formulating guidelines to prepare schools, students, and teachers to come back to offline education after the pandemic. However, there were discrepancies between large universities and small academic centers across the country. Large and well-equipped universities efficiently adapted to changes.

For example, Zhejiang University prepared over 5000 courses in just two weeks, which were made available on the online platform 'Learning at Zhejiang University', attracting 570,000 visitors. Additionally, the university proposed a live streaming app that was used by 300,000 listeners. [7] A similar situation happened at Peking University, where 2613 undergraduate online courses and 1824 graduate online courses were prepared [8]. On the one hand, those data show that technological advantage can be crucial in the educational process continuation. On the other, this type of teaching may be an opportunity to engage students, not only from one university, to participate in courses online.

The shift to online teaching in Vietnam, for instance, forced the universities to use video conferencing tools as a solution that could ensure the effectiveness of distance learning [9]. As a result, 110 out of 240 higher education institutions in Vietnam adapted from traditional education to distance teaching and learning. It is a crucial change, compared to the fact that in 2016 , only $2 \%(33,638)$ of the total of higher education students nationally $(1,581,227)$ were engaged in 'distance learning' [10].

In the United States, one of the perceived COVID-19 pandemic effects may be a drop in enrollment to universities by approximately $15 \%$. A shift to distance learning may also cause tuition cuts if classes remain virtual. Taking into account students' situation during the pandemic, it was already observed that some of them delay graduation or even withdraw from classes [11].

In the Dutch higher education system, difficulties related to the COVID-19 pandemic have also been observed. Students who had the opportunity to study in the Netherlands, but come from outside of the European Union, decided to postpone their studies in Europe. Nevertheless, those students who studied during the pandemic crisis in the Netherlands 
had positively assessed the organizational changes the universities had made to ensure good quality of the education process regarding the circumstances [12].

\subsection{Teaching Policy in Poland-Pandemic Experience}

In Poland, distance learning due to the COVID-19 pandemic was implemented as well. Since March 2020, according to outlines given by the Polish Ministry of National Education, schools have switched to remote teaching, and schools' headmasters have become responsible for organizing the education process [13]. It is worth emphasizing that the switch focused not only on higher education institutions but also on the lower level schools and kindergartens, which closed for students and pupils overnight [14]. The school lockdown in Poland at the first stage of the COVID-19 pandemic was considered to be unprepared, unorganized, and chaotic [13].

The higher education institutes in Poland at that time were in slightly different positions. At the beginning of the epidemic, the decision of the universities' lockdown depended on their authorities. Most public universities decided to shift to distance learning. At the beginning of the new semester in October 2020, the universities' teaching process across Poland was still conducted remotely. Nevertheless, the first stage of the COVID-19 epidemic, dated between March and June 2020, allowed researchers to gather some data about the process of distance learning and to observe its advantages and disadvantages [15]. At this point, preliminary research about the impact of the COVID-19 pandemic on the teaching process and the students' acceptance of remote learning has already been conducted among the students of the University of Economics in Katowice (UEK) Poland. The authors found that students were not entirely convinced about the effectiveness of distance learning and, at that same time, were not sure of their effectiveness in this form of education. On the other hand, they evaluated the tools they used positively as intuitive, along with that of their computer skills. Students declared that they would often use remote teaching methods; however, they would like to return to traditional teaching in the classroom [16].

This particular research's primary objective was to analyze the attitude and expectations of the first-year students of the UEK toward distance learning. When talking about the expectations, the authors mean the feelings and emotions the students expect to have when learning in the distance format, i.e., their attitude toward the methods and tools of online learning before they actually proceeded to applying them. It is important to consider that this group has just started studying, so it does not have the experience of stationary teaching at a higher level. However, at the time of the interview, this group was aware of the Polish government's teaching policy and the fact that it starts to learn remotely. This objective was achieved by surveying first-year students of the University of Economics in Katowice, Poland, before starting their education.

The paper is organized as follows. In Section 2, the literature review is presented, showing the already conducted studies and their results in a field of students' experience of distance learning during the COVID-19 pandemic. In Section 3, the methodology of analysis is presented, and hypotheses are drawn. In Section 4, the authors present their research findings. Section 5 discusses the research results and their practical implications, contributions, and limitations.

\section{Literature Review}

Since the COVID-19 pandemic outbreak, studies have been conducted globally to analyze not only the universities' responses to the new situation [17], but also its impact on students and teachers. Analyses mostly focused on the quality of students' life during a pandemic $[18,19]$, the process of online learning itself [20], and the impact of the pandemic on the situation of higher education institutions as well as the mobility of students [21]. The structure of this literature review considered analyses of the teaching methods implemented during the pandemic period, using online tools in the teaching process, problems the 
teachers struggled with, universities in terms of organizational issues, and, finally, the students' problems.

Reports and studies conducted globally show that there was not one model for teaching classes online. Different platforms and means of communication were used. Students were exposed to a variety of formats replacing on-site lectures, like, for instance, synchronous and asynchronous video lectures [22]. The real-time video conferences were the most frequently used form of distance learning, involving tools such as Microsoft Teams, Zoom, or similar. They were followed by asynchronous forms: sending presentations to students, video recording, and written communication using forums and chats [18,23].

The variety of methods used in the teaching process during the COVID-19 pandemic was problematic not only for students but for the teachers as well. Some of the teachers admitted that, due to poor IT skills, they had a problem in preparing and conducting online classes [24]. But, as researchers stated, one of the positive consequences of online teaching for the teachers was that many of them developed their digital competencies [4], which was motivated and even forced by the existing situation.

What has also been pointed out as a problem for the teachers was that preparing online classes is far more time consuming than on-site lectures [25]. Notable findings were presented by Nash and Churchill. They stated that women teachers working in higher education had decreased their publication records significantly, even by $50 \%$. As the reason, the researchers gave the daily routine of those teachers now involving also the necessity of preparing and recording lectures, as well as still taking care of their children and doing the house chores [26].

The lack of contact with students, especially in primary and secondary schools, deflected teachers' opinions on problems in motivating them [27]. What was also pointed out was the correlation between the effectiveness of online learning with factors such as design and preparation of the materials, the engagement of the teacher, and the possibility of the lecturer-student or student-student interactions [18]. What is more, the quality of communication between teachers and students had already changed. As researchers stated, the teachers needed to change the way of their communication with students in order to advise and guide them, which was particularly observable in academic tutoring [28].

Working remotely was also a challenge for the universities themselves to assure high academic standards of conducted classes as well as the integrity of the teaching process. To achieve this goal, universities needed to prevent and act against academic misconduct [29] and popularize good practice $[30,31]$ in course delivery, students' assessment, and ensuring access to all necessary materials. A change that was reported by teachers in studies, which was correlated with the integrity of the teaching process, concerns, for example, adding new learning content to assigning tasks [32] as well as using "flipped classroom" as a teaching method [33]. The other group of problems universities have faced during the COVID-19 pandemic was related to the infrastructure for online teaching that was either missing or insufficient. Teachers had no experience of working this way, and this lack of experience had an impact on the quality of education [6]. The problem of distance learning was also influenced by the lack of clear information and the complexity of the work and study environment at home [6]. Nevertheless, as some preliminary research shows, teachers admitted the universities were, in fact, supportive for them in the online teaching process [34] by organizing workshops and training to allow teachers to build their competencies in online teaching [7].

Universities and higher education institutions have faced more complicated situations during the COVID-19 pandemic, especially those needing special equipment, laboratories, or face-to-face contact, e.g., medical students with patients. Some researchers have noticed that online learning can be problematic for courses where laboratory presence is required, like drawing, chemistry, electronics [35], and instrumental music [36]. On the other hand, researchers discovered that using Massive Online Open Courses MOOC for teaching journalism and communication has a positive potential, in terms of using technology and improving interactivity among students and tutors [37]. Using MOOCs in teaching 
journalism may be considered as an innovation for this discipline, because in previously conducted studies it was observed that not many universities teaching journalism focus on implementing those solution in the teaching model [38].

The larger group among those related to higher education institutions, affected by the consequences of the COVID-19 pandemic, are students. Studies focusing on students' wellbeing were conducted locally $[20,39]$ (in one particular country), as well as globally $[18,23]$ (internationally). One of them allowed the researchers to obtain information about students' socio-demographic and academic characteristics, academic life, infrastructure and skills for studying from home, networks of support, emotional life, and general reflections on studying from home [23]. As the study showed, the most crucial shift was observed in changing the form of studies. In the same study, it was proven that the majority of students indicated that their study workload was larger than before on-site classes were canceled. Questioned students also showed a drop in academic performance due to lack of a quiet place to study, lack of adequate access to course study material, lack of digital skills, and lack of adequate access to a good Internet connection [23]. The second major study, conducted approximately at the same time (June 2020), analyzed questionnaires from 30,383 students from 62 countries [18]. It focused on how students perceived the impact of the first wave of the COVID-19 crisis on their lives in various aspects. The students' emotional distress is one of the results of the COVID-19 pandemic. The research, conducted in Bangladesh in May 2020, shows that feelings of anxiety, also pointed out in previously quoted research, are relatively common among the students in that country [39]. The study conducted in Saudi Arabia showed that most of the interviewed students felt they were affected by shifting the education process online [20].

Students' attitude toward distance learning revealed both advantages and disadvantages of the process, assessed from students' perspectives. Every presented study result showed that the COVID-19 pandemic has impacted students and forced a shift to distance learning. It is related to the organization of the teaching process, the Internet tools used in the process, and the students' well-being. Most of the studies presented were conducted shortly after schools and higher education institutions had been closed and focused on the experience of students who needed to adapt to the new educational system based on online teaching.

From the studies already conducted, one can conclude that, among students worldwide, one can distinguish several main problems related to the COVID-19 pandemic. The first group involves students' well-being and daily life during the pandemic. They experienced negative emotions such as boredom, anxiety, frustration, anger, hopelessness, and shame, as well as mild to severe depressive symptoms [18,39]. Those emotions often correlated with social isolation, which was stated as one of the most important issues during the pandemic [40]. Questioned students also pointed out that the shift to distance learning was rather demanding in terms of time management. Most students admitted that their workload at some point had become larger or significantly larger than previously [18,23].

The studies also show a drop in students' academic performance due to lack of a quiet place to study, lack of adequate access to course study material, lack of digital skills, lack of adequate access to a good Internet connection [23], design and preparation of the materials, the engagement of the teacher [18], insufficient help they were able to get through online tools, and the difficulty of understanding the materials they needed to work on by themselves [20].

On the other hand, students pointed out that online learning in terms of using technology is not demanding for them. Most of the questioned students admitted that they felt confident in using online tools [23], not only for learning purposes but also as an effective way for stress management, advised by the university [41]. Using the technology to maintain social contacts, as Raaper and Brown state, has a significant impact on students' mental and physical well-being, making students' social networks an essential tool of support during the pandemic period [42]. In case of contact with academic staff, students admitted that tools such as Facebook or email were sufficient to solve arising problems. 
Also, what can be considered as a non-obvious result of distant learning and staying at home during the pandemic period, questioned students admitted that during the time of isolation, they had tightened their bonds with family members and friends [43].

A significantly important group of students is the one that has just started their education at universities or colleges. Studies show that students' motivation relates to both engagement and attachment to the university [44]. The time of online studying is particularly challenging for those who did not have wide experience with online studying before. As the study conducted previously showed, there are differences in motivation between a group of students who have been shifted to distance learning and those who have started online learning from the beginning of their studies at universities [44]. As the researchers state, a necessity to adapt to different conditions of studying in a short period of time, as well as the lack of experience with online studying, could result in reducing the proactive involvement in the process [44].

Based on the previously conducted studies, as well as to focus on the first-year students as a particular group of students, the Authors decided to diagnose their expectations toward online learning instead of the experience of the groups that had already been studying.

\section{Materials and Methods}

Structural Equation Modeling (SEM) is a set of methods for exploring relationships between variables. Partial Least Squares (PLS) is a statistical method that can be applied for a small sample testing and leads to the prediction of indicators. It also allows putting forward hypotheses for the variables that have a complex impact on the particular aspects of the model. The predicted and the observed variables are projected to a new space with the linear regression.

\subsection{Hypotheses Development}

The variables to be analyzed with the SEM method are developed based on the TAM (Technology Acceptance Model), which was developed by F. Davis in 1986 [45] and took its roots in the ToRA (psychological Theory of Reasoned Action) that assumes that people believe that they can execute the behavior whenever they are willing to do so. The TAM contains five variables referring to the acceptance of technology by users: the perceived usefulness of the technology, the perceived ease of use of the technology by a user, the attitude (of a user) toward using the technology, the intention (of a user) to use the technology, and the actual use of the technology by a user. Following the concept of the model, it can be stated that the perceived ease of use and the perceived usefulness of technology are predictors of the user's approach toward using the technology (i.e., user's Attitude Toward Using), user's subsequent behavioral intentions (i.e., user's Intention to Use), and Actual Use. The Perceived Ease of Use is often observed to also influence the Perceived Usefulness of technology [46]. In addition to the five core variables, the TAM also includes External Variables connected with the major variables by affecting the Perceived Usefulness and Perceived Ease of Use. Yet, the original TAM does not contain any expanded description of these variables. To fill this gap, Abdullah and Ward [47] developed the GETAMEL (General Extended Technology Acceptance Model for E-Learning), where they elaborated on the external factors and distinguished the following indicators: Experience, Subjective Norms, Enjoyment, Computer Anxiety, and Self-Efficacy.

Thus, altogether, the authors included 10 variables to be analyzed with PLS-SEM, with the objective to explore the attitude and, before all else, expectations of the first-year students of the selected higher education institution. Five external variables are to be presented first, then followed by five core TAM variables.

\subsubsection{Experience $(\mathrm{XP})$}

In the context of the Technology Acceptance Model and GETAMEL, Experience (as for computers) is referred to as the amount and type of skills that a user steadily gains [48]. Previous research revealed that XP affects both the Perceived Ease of Use and the Perceived 
Usefulness of learning with the help of computers [49]. Experience is considered as one of the most important external factors influencing technology acceptance. Following the general GETAMEL principles, the authors came up with the following two hypotheses:

Hypothesis 1 (H1). Students' Experience in the distance learning process has a positive impact on their Perceived Usefulness of distance learning.

Hypothesis 2 (H2). Students' Experience in the distance learning process has a positive impact on their Perceived Ease of Use of distance learning tools.

\subsubsection{Subjective Norms (SN)}

The studies conducted by Ching-Ter et al. and Agudo-Peregrina et al. [50,51] refer to Subjective Norms as a person's attitude to the opinion of the people that are most important for this person; the opinion is particularly about a specific behavior this person should or should not perform. In the context of distance learning, $\mathrm{SN}$ are defined as the degree to which a student perceives pressure from members of this student's family or friends in the issue of usage of distance learning technologies. In other words, it can be stated that Subjective Norms are opinions of other people around a student (social environment) as for the studies and the activities this student performs. When studying the effect of the SN on other factors, Venkatesh and Davis [52], for instance, revealed that SN is negatively related to the Perceived Usefulness, but that it has a positive and significant impact on the student's Intention to Use. To confirm or challenge this (another) finding, the authors have put forward the two hypotheses for Subjective Norms in distance learning:

Hypothesis 3 (H3). Students' subjective norms in the distance learning process have a positive impact on their Perceived Usefulness of distance learning.

Hypothesis 4 (H4). Students' subjective norms in the distance learning process have a positive impact on their Perceived Ease of Use of tools applied in distance learning.

\subsubsection{Enjoyment (ENJ)}

In the context of using technology for learning, Enjoyment is connected with the activity of using technology and perceiving it to be engaging and pleasing [53]. Studies on Enjoyment in e-learning, distance learning, and various learning systems have shown that ENJ has a significant positive influence on the Perceived Usefulness of learning technologies $[54,55]$. The authors would like to further explore the influence of Enjoyment on other variables. That is why the following hypotheses were proposed:

Hypothesis 5 (H5). Perceived Usefulness of the distance learning process is positively affected by Students' Enjoyment of this process.

Hypothesis 6 (H6). Students' Perceived Ease of Use of tools used for distance learning is positively affected by their Enjoyment of the distance learning process.

\subsubsection{Computer Anxiety (CA)}

CA is defined by researchers as the tendency of a user to feel strained or terrified by the current or potential use of any computers or any other technology [56]. CA is believed to have a significant negative effect on students' Intention to Use learning technology and on their performance in learning. People who consider computers too complicated might avoid using them and might have convinced themselves that they cannot use them at all $[53,57]$. The following hypotheses were put forward by the authors to analyze CA's effect on core factors of the Technology Acceptance Model:

Hypothesis 7 (H7). Students' Perceived Usefulness of distance learning is negatively affected by Computer Anxiety, confronted by students in the distance learning process. 
Hypothesis 8 (H8). Students' Perceived Ease of Use of distance learning tools is negatively affected by Computer Anxiety, experienced by students in the distance learning process.

\subsubsection{Self-Efficacy (SE)}

SE of a computer user is understood as the user's belief to be able to perform a certain task using a computer [58]. The authors wanted to prove that SE positively influences the Perceived Ease of Use and the Perceived Usefulness of students in the distance learning process. That is why the two hypotheses were put forward:

Hypothesis 9 (H9). Perceived Usefulness of the distance learning process is positively influenced by Self-Efficacy that students experience while learning.

Hypothesis 10 (H10). Perceived Ease of Use of distance learning tools is positively influenced by Self-Efficacy that students experience while learning.

\subsubsection{Perceived Usefulness (PU)}

Researchers point out that the PU and Perceived Ease of Use affect students' Intention to Use learning technologies. Some works also reveal the effect of Perceived Ease of Use on the PU. Perceived Usefulness is referred to as the extent to which a user believes that a particular technology used would improve the user's work/study performance, compared to the alternative methods [59]. With the objective to continue exploring students expectations of distance learning, the authors proposed the two hypotheses (following the TAM principles):

Hypothesis 11 (H11). Attitude (of students) Toward Using distance learning tools is positively affected by students' Perceived Usefulness of learning distantly.

Hypothesis 12 (H12). Students' Intention to Use the tools for distance learning is positively affected by students' Perceived Usefulness of distance learning.

\subsubsection{Perceived Ease of Use (PEOU)}

As Esteban-Millat et al. [60] suggest, the PEOU is a degree to which a user of a learning system believes that using this system will be uncomplicated for this user. The PEOU is believed to be a certain predictor of users' Attitude Toward Using the technology and their Intention to Use. To explore the influence of the PEOU on Technology Acceptance Model core variables, the authors developed the following hypotheses:

Hypothesis 13 (H13). Perceived Ease of Use of the tools used in distance learning has a positive effect on students' Perceived Usefulness of such education.

Hypothesis 14 (H14). Perceived Ease of Use of the tools for distance learning positively affects students' Attitude Toward Using these tools.

\subsubsection{Attitude toward Using (ATU)}

Both in the Technology Acceptance Model and GETAMEL, the ATU is influenced by the Perceived Ease of Use and the Perceived Usefulness. The Attitude Toward Using is believed to have an impact on the Intention to Use [56]. Masrom conducted a survey that showed that the Attitude Toward Using does not affect students' Intention to Use learning technologies [46]. To confirm or disprove this finding, the authors hypothesized about students' ATU in distance learning:

Hypothesis 15 (H15). Students' Attitude Toward Using distance learning tools positively affects their Intention to Use distance learning tools. 


\subsubsection{Intention to Use (ITU)}

The ITU of distance or e-learning is referred to as the students' intent to employ learning systems. It has been shown in many studies that the ITU directly and significantly influences the Actual Use of technologies applied for learning [61]. The following hypothesis was put forward to analyze the Intention to Use in distance learning:

Hypothesis 16 (H16). Students' Intention to Use distance learning tools positively affects the Actual Use of these tools.

\subsubsection{Actual Use (AU)}

The AU is the last (definitely not the least) core factor of the TAM model. The Actual Use of learning technology is the result of the interconnection of the other factors mentioned above. Thus, the AU does not have any impact on the abovementioned components of the TAM.

\subsection{Methodology}

The methodology employed the structural modeling equation with the partial least squares' version (PLS-SEM). The methodology follows the protocol established by Sarstedt et al. [62], Hair et al. [63], and Henseler et al. [64]. First, model reliability with the measurement quality was assessed, and then the hypotheses were tested. Figure 1 presents the distance learning model, as displayed in the SmartPLS 3 [65]. The model was taken from the work of Abudallah and Ward [47] and was published as a GETAMEL (General Extended Technology Acceptance Model for E-Learning). In this work, the concept was used as the background for the study, with necessary adaptations. All the external variables (Experience, Subjective Norms, Computer Anxiety, Enjoyment, Computer Anxiety, and Self-Efficacy) were kept. With this approach, the Technology Acceptance Model (TAM) was combined with external factors. Adaptation to the current situation in the COVID-19 pandemic entailed preparing items used in the survey to reflect expectations after mandatory switching to distance learning.

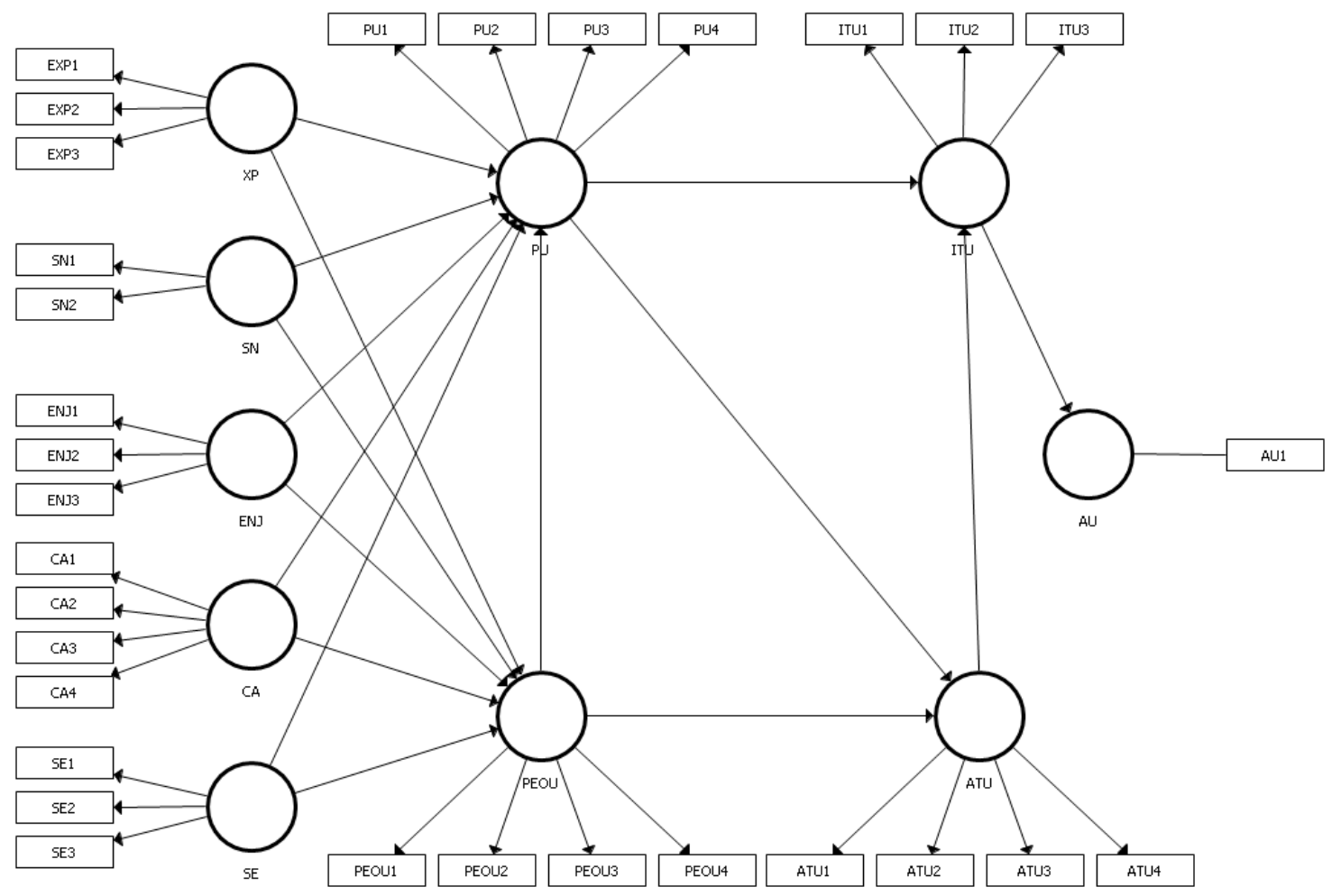

Figure 1. Expectations in the distance learning model. 


\section{Results}

The data for assessing the structural model and the testing proposed hypotheses were collected with a questionnaire in Google Forms. This questionnaire was already tested in a previous study [16]. This study was adjusted to measure expectations, and one additional variable (Subjective Norms) was added to the list. The adjusted final set of questions was sent to all students starting their studies at the UEK. The questionnaire was released on 30 September 2020. The invitation was sent twice. We wanted to ask students about their expectations before they started their education. Most of the data came in the first week. All recruited first-year students, in the number of 1190, were asked to take part in the study by receiving a personalized email request. The questionnaire collected 670 answers, which is $56.3 \%$ of the first-year students' entire population at the university. The respondents' structure is described in Table 1.

Table 1. Respondents' data.

\begin{tabular}{ccc}
\hline Sex & $\mathbf{N}$ & $\%$ \\
\hline Woman & 372 & $55.5 \%$ \\
Man & 596 & $44.5 \%$ \\
Subject/Field of study & & \\
Computer Science and Econometrics & 35 & $5.2 \%$ \\
Economic Analysis & 18 & $2.7 \%$ \\
Economics & 73 & $10.9 \%$ \\
Economy and Public Management & 13 & $1.9 \%$ \\
Entrepreneurship and Finance & 31 & $4.6 \%$ \\
Finance and Accounting & 173 & $25.8 \%$ \\
Finance and Management in Healthcare & 15 & $2.2 \%$ \\
Informatics & 41 & $6.1 \%$ \\
International Business & 35 & $5.2 \%$ \\
International Economic Relations & 35 & $5.2 \%$ \\
Journalism and Social Communication & 20 & $3.0 \%$ \\
Logistics & 41 & $6.1 \%$ \\
Logistics in Business & 33 & $4.9 \%$ \\
Management & 52 & $7.8 \%$ \\
Managerial Finances & 25 & $3.7 \%$ \\
Spatial Planning & 21 & $3.1 \%$ \\
Tourism Economy & 9 & $1.3 \%$ \\
\hline
\end{tabular}

Next, the data were examined. The structure of the survey guaranteed no missing values. Six answers were excluded because the estimated variance was zero, by respondents marking the same value for every question. Finally, 664 data responses were used for estimation. The size of the sample proved to be more than sufficient for the PLS-SEM path model examination.

The model calculation executed in this study was estimated with the primary PLS-SEM algorithm. The basic settings were the weighting scheme (centroid, maximum iterations 300 , stop criterion $1 \times 10^{7}$ ) and started with equal indicator weights. Figure 2 displays the PLS-SEM scores. The results shown in the constructs' circles are $R^{2}$ values, whereas results on the path relationships represent the standardized regression coefficients. 




Figure 2. Expectations of the first-year students in the distance learning and results.

Our model included only reflectively measured construct, which means all singleheaded arrows were pointing from dependent variables to indicators. In the first step, by checking indicator reliability, internal consistency reliability, convergent validity, and discriminant validity, we estimated the quality of data indicators. After assessing the sufficient quality of data, in the second step we evaluated model prediction capabilities by checking collinearity, $R^{2}$ explanation of latent variables, significance and relevance of path coefficient, and $f^{2}$ effect size.

Table 2 presents the results of the assessment of the measurement model. The authors found that all (except ITU1-Intention to Use 1) reflective measurement models met the assessment criteria from the research protocol [62]. All the outer weights (except ITU1) were higher than 0.70 , confirming that all indicators reached a necessary level of reliability (i.e., $>0.70$ ). All the Average Variance Extracted values were higher than 0.50, which confirmed the convergent validity. Composite reliability had values of at least 0.784 , which was clearly higher than the limit. Cronbach's alpha range was between 0.624 and 0.941 ; these numbers were satisfactory for this research. Finally, all reliability rho_A values higher than 0.70 were least acceptable. These scores confirmed that all construct measures reached acceptable levels of internal consistency reliability. 
Table 2. Measurement model and assessment results for PLS-SEM.

\begin{tabular}{|c|c|c|c|c|c|c|c|}
\hline \multirow{3}{*}{$\begin{array}{c}\text { Latent } \\
\text { Variable }\end{array}$} & \multirow{3}{*}{ Indicators } & \multicolumn{3}{|c|}{ Convergent Validity } & \multicolumn{3}{|c|}{ Internal Consistency Reliability } \\
\hline & & Loadings & Reliability & AVE & $\begin{array}{c}\text { Composite } \\
\text { Reliability } \rho c\end{array}$ & $\begin{array}{l}\text { Reliability } \\
\rho A \text { (rho_A) }\end{array}$ & $\begin{array}{c}\text { Cronbach's } \\
\text { Alpha }\end{array}$ \\
\hline & & $>0.70$ & $>0.50$ & $>0.50$ & $>0.70$ & $>0.70$ & $0.70-0.95$ \\
\hline \multirow{5}{*}{ ATU } & ATT1 & 0.844 & 0.712 & \multirow{5}{*}{0.759} & \multirow{5}{*}{0.926} & \multirow{5}{*}{0.909} & \multirow{5}{*}{0.894} \\
\hline & ATT2 & 0.912 & 0.832 & & & & \\
\hline & ATT3 & 0.906 & 0.821 & & & & \\
\hline & ATT4 & 0.819 & 0.671 & & & & \\
\hline & CA1 & 0.819 & 0.671 & & & & \\
\hline \multirow{3}{*}{ CA } & CA2 & 0.841 & 0.707 & \multirow{3}{*}{0.761} & \multirow{3}{*}{0.927} & \multirow{4}{*}{0.911} & \multirow{4}{*}{0.896} \\
\hline & CA3 & 0.913 & 0.834 & & & & \\
\hline & CA4 & 0.913 & 0.834 & & & & \\
\hline \multirow{4}{*}{ ENJ } & ENJ1 & 0.950 & 0.903 & \multirow{4}{*}{0.895} & \multirow{4}{*}{0.962} & & \\
\hline & ENJ2 & 0.951 & 0.904 & & & \multirow[t]{3}{*}{0.942} & \multirow[t]{3}{*}{0.941} \\
\hline & ENJ3 & 0.937 & 0.878 & & & & \\
\hline & ITU1 & 0.449 & 0.202 & & & & \\
\hline \multirow[t]{3}{*}{ ITU } & ITU2 & 0.857 & 0.734 & \multirow[t]{3}{*}{0.565} & \multirow[t]{3}{*}{0.784} & \multirow[t]{3}{*}{0.750} & \multirow[t]{3}{*}{0.624} \\
\hline & ITU3 & 0.872 & 0.760 & & & & \\
\hline & PEOU1 & 0.893 & 0.797 & & & & \\
\hline \multirow{3}{*}{ PEOU } & PEOU2 & 0.893 & 0.797 & \multirow{4}{*}{0.776} & \multirow{4}{*}{0.933} & \multirow{4}{*}{0.904} & \multirow{3}{*}{0.904} \\
\hline & PEOU3 & 0.898 & 0.806 & & & & \\
\hline & PEOU4 & 0.839 & 0.704 & & & & \\
\hline & PU1 & 0.930 & 0.865 & & & & \\
\hline & PU2 & 0.923 & 0.852 & & & & \\
\hline PU & PU3 & 0.932 & 0.869 & 0.829 & 0.951 & 0.931 & 0.931 \\
\hline & PU4 & 0.854 & 0.729 & & & & \\
\hline & SE1 & 0.922 & 0.850 & & & & \\
\hline SE & SE2 & 0.948 & 0.899 & 0.879 & 0.956 & 0.935 & 0.931 \\
\hline & SE3 & 0.943 & 0.889 & & & & \\
\hline & SN1 & 0.951 & 0.904 & & & & \\
\hline SN & SN2 & 0.958 & 0.918 & 0.911 & 0.953 & 0.906 & 0.902 \\
\hline & $\mathrm{XP1}$ & 0.856 & 0.733 & & & & \\
\hline $\mathrm{XP}$ & XP2 & 0.868 & 0.753 & 0.753 & 0.901 & 0.902 & 0.843 \\
\hline & XP3 & 0.879 & 0.773 & & & & \\
\hline
\end{tabular}

The conditionally accepted indicator was ITU1. Its mean was 6.62 on a scale of 1 to 7 , and SD was 0.72 . It was known that distance learning would be obligatory for winter semester 2020/21, and respondents were asked whether they intended to take part in distance learning. Most of the respondents shared the highest intention. ITU1 was left in the model since its deletion would have led to exceeding the criteria for HeterotraitMonotrait Ratio (HTMT) threshold. Removing ITU1 was also tested, and it did not influence results in the hypotheses testing.

Finally, the discriminant validity was calculated with the use of the HTMT criterion. All the scores were below the level of 0.90 (Table 3). Next, the bootstrapping algorithm with 5000 samples was deployed, and the complete bootstrapping setting was set, along with the Bias-Corrected and Accelerated confidence intervals and two-tailed test type at the significance level of 0.05 . The HTMT confidence intervals scores did not have a value of 1, confirming that all the HTMT values were undoubtedly distinct from 1. 
Table 3. Heterotrait-Monotrait Ratio (HTMT).

\begin{tabular}{cccccccccc}
\hline & XP & SN & SE & PU & PEOU & ITU & ENJ & CA & AU \\
\hline SN & 0.333 & & & & & & & & \\
\hline SE & 0.608 & 0.408 & & & & & & \\
\hline PU & 0.418 & 0.554 & 0.609 & & & & & & \\
\hline PEOU & 0.727 & 0.383 & 0.757 & 0.566 & & & & \\
\hline ITU & 0.540 & 0.672 & 0.605 & 0.799 & 0.639 & & & \\
\hline ENJ & 0.672 & 0.588 & 0.699 & 0.770 & 0.753 & 0.857 & & & \\
\hline CA & 0.733 & 0.073 & 0.461 & 0.213 & 0.488 & 0.224 & 0.361 & & \\
\hline AU & 0.381 & 0.537 & 0.448 & 0.531 & 0.438 & 0.827 & 0.546 & 0.209 & \\
\hline ATU & 0.457 & 0.594 & 0.606 & 0.831 & 0.581 & 0.872 & 0.837 & 0.294 & 0.560 \\
\hline
\end{tabular}

The following effects for path coefficients presented in Table 4 were received. Twelve hypotheses were significant at a 0.05 error level, while four effects were not confirmed. Hypotheses H4, H7, H8, and H13 were not supported.

Table 4. Hypotheses testing results with statistics.

\begin{tabular}{cccccc}
\hline Hypothesis & Coefficient & T-Statistics & Confidence Interval & $f^{2}$ Effect Size & $\begin{array}{c}\text { Significant } \\
(\boldsymbol{p}<\mathbf{0 . 0 5} \boldsymbol{?}\end{array}$ \\
\hline H1 & -0.137 & 3.196 & $(0.221,-0.053)$ & 0.016 & Yes \\
H2 & 0.271 & 6.159 & $(0.185,0.357)$ & 0.080 & Yes \\
H3 & 0.154 & 4.417 & $(0.085,0.220)$ & 0.037 & Yes \\
H4 & -0.037 & 1.228 & $(-0.095,0.022)$ & 0.003 & No \\
H5 & 0.587 & 13.385 & $(0.498,0.673)$ & 0.282 & Yes \\
H6 & 0.315 & 6.851 & $(0.224,0.402)$ & 0.106 & Yes \\
H7 & -0.016 & 0.483 & $(-0.081,0.050)$ & 0.000 & No \\
H8 & 0.027 & 0.782 & $(-0.039,0.095)$ & 0.001 & No \\
H9 & 0.194 & 4.540 & $(0.109,0.279)$ & 0.038 & Yes \\
H10 & 0.337 & 9.351 & $(0.266,0.408)$ & 0.158 & Yes \\
H11 & 0.673 & 25.379 & $(0.622,0.725)$ & 0.852 & Yes \\
H12 & 0.311 & 6.901 & $(0.221,0.399)$ & 0.094 & Yes \\
H13 & 0.023 & 0.498 & $(-0.069,0.115)$ & 0.000 & No \\
H14 & 0.180 & 5.881 & $(0.120,0.238)$ & 0.061 & Yes \\
H15 & 0.494 & 11.418 & $(0.408,0.578)$ & 0.238 & Yes \\
H16 & 0.688 & 28.160 & $(0.638,0.733)$ & 0.898 & Yes \\
\hline
\end{tabular}

Multigroup analysis with PLS-SEM was performed for testing differences between groups [66]. In this model, a variable gender was tested. However, there were no significant differences between groups, considering this variable.

\section{Discussion}

The initial assessment of Perceived Usefulness' key predictors (Table 4), which had a considerable $R^{2}$ value of 0.568 , found that Enjoyment had the robust significant positive effect (0.587) (H5), followed by Self-Efficacy (0.194) (H9) and Subjective Norms (0.154) (H3). Experience had a negative effect $(-0.137)(\mathrm{H} 1)$, while Computer Anxiety $(-0.016)(\mathrm{H} 7)$ was not significant. Perceived Ease of Use had a considerable $R^{2}$ value of 0.634 . Self-Efficacy $(0.337)(\mathrm{H} 10)$, Enjoyment $(0.315)(\mathrm{H} 6)$, and Experience $(0.271)(\mathrm{H} 2)$ had the substantially significant effect. On the contrary, the effects of Computer Anxiety (0.027) (H8) and SN $(-0.037)(\mathrm{H} 4)$ on PEOU were not significant at the $5 \%$ level.

In this model, the strongest external predictor of Perceived Usefulness and Perceived Ease of Use was Enjoyment, followed by Self-Efficacy. We observed that students were happy and comfortable with participating in classes from their homes, often from their 
rooms. It was a new situation, and they were enjoying it. Self-Efficacy was the second strongest external predictor. Students were confident that they will be able to follow different tasks using computer software for distance learning. They will receive help, if needed, from the academic teacher, on how to conduct and solve various tasks during online classes.

In this study, hypothesis $\mathrm{H} 1$ was confirmed; however, the observed effect was negative. The previous literature results showed that this effect of Experience on Perceived Usefulness was usually positive [47]. It could be caused by increasing users' experience in using different computer software. A limited number of online learning platforms are available to conduct distance learning with full engagement in COVID-19 pandemic time [67]. Rapid migration to online learning platforms was not planned [68]. These platforms were instantly updated to ensure that they could provide the environment to study and address demanding challenges and e-learning procedure factors during this epidemic [69]. Students were aware of these constant updates since they are part of it. Their experience related to other computer software negatively affected the perceived usability of computer software utilized in distance learning.

Hypotheses H7 and H8 concerning Computer Anxiety were not supported. In previous literature, the effect of Computer Anxiety on Perceived Usefulness was not significant; the effect of Computer Anxiety on Perceived Ease of Use was usually negative [47]. In this model, for measuring Computer Anxiety, items with inverted scales were used. It was expected that at least one hypothesis was supposed to be supported as having a positive effect. Yet, results showed that Computer Anxiety did not significantly affect either Perceived Usefulness or Perceived Ease of Use. This variable was developed about 20 years ago when computers were not in every home. Nowadays, students usually have their personal computers. They use them very often, especially since the beginning of the school year. They use them very naturally and confidently, and they often know more about current technology than teachers. This is why they do not manifest computer anxiety. In the previous study, hypothesis $\mathrm{H} 8$ (CA $\geq$ PEOU) was also not confirmed, while hypothesis H7 (CA $\geq \mathrm{PU}$ ) was supported; however, its $f^{2}$ effect size was very small (less than 0.02) [16].

The third not-supported hypothesis was H4. It concerned the effect of Subjective Norms on Perceived Ease of Use. There was no critical effect of Subjective Norms on Perceived Ease of Use. The current situation made distance learning and taking part in online classes mandatory. It did no longer depend on the influence of students' close relationships with other persons. Students need to be active in distance learning, as warranted by the official government act in Poland. The fourth not-supported hypothesis was H13. In this model, there was no important effect of Perceived Ease of Use on Perceived Usefulness. Perceived Ease of Use and Perceived Usefulness are the primary dependent constructs of the TAM. The GETAMEL model is built to estimate the effect sizes of external variables on TAM's primary constructs. The relation between Perceived Usefulness and Perceived Ease of Use was enclosed in the model; however, results showed that this relationship was not significant.

We advanced the current research on shifting higher education to online learning studies in the following areas. We tested a full GETAMEL model with all external variables and core TAM variables compared to a theoretical contribution from previous studies. Aguilera-Hemida [70] conducted a similar survey among American students, but variables were mixed between qualitative and quantitative items and there was no clear model representation. Siron et al. [71] conducted a similar study among Indonesian students and presented an adapted model from GETAMEL; however, only four external variables and two core TAM variables were used. In their study, Experience, Computer Anxiety, and Self-Efficacy had no significant effect on Perceived Usefulness when, in this model, only Computer Anxiety was identified as not having a significant effect. 


\subsection{Contributions}

The research presented in this paper was conducted in autumn 2020, i.e., more than half a year after the COVID-19 pandemic outbreak happened in Poland, causing higher education institutions all over the country to switch to distance learning. Within this period, a lot of research was conducted on coronavirus influence on education policies and teaching and learning experience. In the authors' point of view, the first contribution of this research is the review that allowed them to structure the previous findings and, as a result, the state-of-the-art knowledge on the consequences of coronavirus in the educational sector.

The study was conducted in a group of the first-year students who were just about to begin their studies in the university's distance learning. The authors see the second contribution in the fact that the respondents were not familiar with such a learning format before and could express only their expectations. Besides, the authors consider it important that these students (when being enrollees) were aware of the fact that they will have to study online and yet they have applied for studies-i.e., they have started the study process being conscious of its format, of advantages, and possible disadvantages.

The third contribution is connected with the hypotheses set in the paper, namely, with $\mathrm{H1}, \mathrm{H} 4, \mathrm{H7}$, and H8. Hypothesis 1 showed a negative effect of Experience on Perceived Usefulness, which differs from the previous research results. Hypotheses 7 and 8 revealed that Computer Anxiety does not have a significant influence (neither positive nor negative) on Perceived Usefulness and Perceived Ease of Use. In contrast, in other research, its influence was mostly negative. Furthermore, Hypothesis 4 allowed developing an interesting yet rather expected conclusion: Subjective Norms (like family or friends' opinions) do not influence students' Perceived Ease of Use of distance learning. Although these opinions are generally valuable for the respondents, they cannot change the fact that they have to participate (and be actively engaged) in distance learning during the pandemic period. Finally, the work contributes to the science of didactic process management in general. It can be used as a basis for further research dedicated to distance learning or for conducting improvements to the currently running process of distance education in the pandemic period [72].

\subsection{Practical Implications}

Students' experience in the process of distance learning makes them believe that they will learn more remotely than during classroom activities. Their high computer skills mean that they do not worry that distance learning can cause them technical difficulties (related to the use of tools). The perception of distance learning by people who are important to students or impact their behavior has a positive effect on how students assess Perceived Usefulness. At the same time, these people's opinions did not correlate positively with how students assess the ease of participating in distance learning.

The enjoyment correlates with Perceived Usefulness. Students are unlikely to be satisfied with the fact that there is distance learning, and they do not enjoy it. Enjoyment is also correlated with the ease of use of the tools. Most students have no concerns about using the computer. No impact of possible anxiety on the Usefulness of distance learning or its Easiness was observed.

Students' feeling of Self-Efficacy positively influenced the Perceived Usefulness rating and the Ease of Use. When students think that they can get more from distance learning than from traditionally conducted classes (Perceived Usefulness), their overall assessment (Attitude Toward Using) of remote learning increased. The involvement of students in the process (Intention to Use) also increased. Similarly, when students were good at distance learning, it did not cause them technical problems (Perceived Ease of Use). They judged the idea of introducing remote education (Attitude Toward Using) as better.

At the same time, how they cope with technical tools did not change their assessment of whether they will gain more knowledge than stationary (Perceived Usefulness). The assessment (Attitude Toward Using) of distance learning impacted students' engagement 
in the process (Intention to Use). The better they evaluated distance learning, the more they were involved in it. Students' involvement and their willingness to use remote learning tools influenced whether or not they used these tools.

All of the indicated results can be used by teachers conducting classes in distance learning format at a higher level [73]. The information collected through the research shows not only the expectations of students toward distance learning but also their abilities to use IT tools in this process, their enjoyment of the process, and their expectations toward teachers and their engagement. Therefore, the most important practical implication of the study presented is the teachers' possibility to improve their teaching process by applying solutions according to students' expectations, for instance, by paying more attention to the teacher-student interaction and, with this, by keeping the distance learning more "human" despite the presence of a computer screen between the participants of the process.

\subsection{Limitations and Further Research Work}

The main limitation of the conducted study is its geographical range. The interviewed students are currently studying only at one university from Katowice, Poland. There are other higher education institutions, such as Silesian University, Silesian Medical University, or Silesian University of Technology, whose students were not interviewed.

The study was conducted at the University of Economics in Katowice. At this particular university, students can study one of the following disciplines: economics, management, accounting, IT, or journalism. Therefore, the university's profile where the interviewed students came from can be understood as a limitation for the study. The university's profile limits students enrolling in it to only those interested in studies in the disciplines mentioned above. Although in the research, students participated from different fields of study, such as Accounting, Informatics, Journalism and Social Communication, and Economics, the Authors did not correlate the answers given in the questionnaire with this particular variable, which can also be understood as a limitation for the research.

The last limitation for the conducted research was previous experiences of the students obtained at the time of the first phase of the global COVID-19 pandemic, while they were still in high school. The organization of the process of distance education, the used tools, and the uncertainty caused by the government decision at that time could have affected the students' expectations toward the process of distance learning offered by the University of Economics. However, at that point, it is merely an assumption.

Taking into account the limitations stated above, the following steps are recommended for the verification in any future research.

- By measuring the results of this particular study with another student group of the same university, but of a higher year, it will be possible to verify discrepancies in expectations of both of these groups.

- By comparing, using the same questionnaire, the expectations of first-year students next year it will be possible to determine if the online education conducted on a high school level, which lasted longer than in the case of interviewed students, can be a factor influencing their expectations toward distance learning provided by the university.

- By conducting research correlating with the field of study chosen by the interviewed students with their expectations toward online education provided by the universitybecause among fields of study offered only by the University of Economics in Katowice, where the presented research took place, there are not only those related to economics but also such related to social sciences--the proposed research may point out the differences in expectation corresponding to the students' field of study.

- Conduct similar research on a larger scale involving a larger group of Polish universities. 
Author Contributions: Conceptualization, K.C., P.R., M.R., and A.S.; investigation, K.C., P.R., M.R., and A.S.; resources, A.S.; data curation, M.R. and A.S.; writing-original draft preparation, K.C.; writing-review and editing, K.C. and M.R.; funding acquisition, K.C. and A.S. All authors have read and agreed to the published version of the manuscript.

Funding: This research was funded by the Ministry of Science and Higher Education of Poland for the University of Economics in Katowice for 2021.

Ethical Approval: This article does not contain any studies with human participants or animals performed by any of the authors. Informed consent was obtained from all individual participants included in the study. The survey was completely anonymous.

Institutional Review Board Statement: Not applicable.

Informed Consent Statement: Informed consent was obtained from all subjects involved in the study.

Conflicts of Interest: The authors declare no conflict of interest.

\section{References}

1. Strzelecki, A.; Azevedo, A.; Albuquerque, A. Correlation between the Spread of COVID-19 and the Interest in Personal Protective Measures in Poland and Portugal. Healthcare 2020, 8, 203. [CrossRef]

2. Staszkiewicz, P.; Chomiak-Orsa, I.; Staszkiewicz, I. Dynamics of the COVID-19 contagion and mortality: Country factors, social media, and market response evidence from a global panel analysis. IEEE Access 2020, 8, 106009-106022. [CrossRef]

3. Pagach, D.; Wieczorek-Kosmala, M. The Challenges and Opportunities for ERM Post-COVID-19: Agendas for Future Research. J. Risk Financ. Manag. 2020, 13, 323. [CrossRef]

4. Kerres, M. Against all odds: Education in Germany coping with COVID-19. Postdigital Sci. Educ. 2020, 2, 1-5. [CrossRef]

5. Küsel, J.; Martin, F.; Markic, S. University students' readiness for using digital media and online learning-comparison between Germany and the USA. Educ. Sci. 2020, 10, 313. [CrossRef]

6. Zhang, W.; Wang, Y.; Yang, L.; Wang, C. Suspending classes without stopping learning: China's education emergency management policy in the COVID-19 outbreak. J. Risk Financ. Manag. 2020, 13, 55. [CrossRef]

7. Yang, R. China's higher education during the COVID-19 pandemic: Some preliminary observations. High. Educ. Res. Dev. 2020, 39, 1317-1321. [CrossRef]

8. Bao, W. COVID-19 and online teaching in higher education: A case study of Peking University. Hum. Behav. Emerg. Technol. 2020, 2, 113-115. [CrossRef]

9. Pho, D.-H.; Nguyen, X.-A.; Luong, D.-H.; Nguyen, H.-T.; Vu, T.-P.-T.; Nguyen, T.-T.-T. Data on Vietnamese students' acceptance of using VCTs for distance learning during the COVID-19 pandemic. Data 2020, 5, 83. [CrossRef]

10. Pham, H.-H.; Ho, T.-T.-H. Toward a 'new normal' with e-learning in Vietnamese higher education during the post COVID-19 pandemic. High. Educ. Res. Dev. 2020, 39, 1327-1331. [CrossRef]

11. Aucejo, E.M.; French, J.; Ugalde Araya, M.P.; Zafar, B. The impact of COVID-19 on student experiences and expectations: Evidence from a survey. J. Public Econ. 2020, 191, 104271. [CrossRef]

12. de Boer, H. COVID-19 in Dutch higher education. Stud. High. Educ. 2021, 46, 96-106. [CrossRef]

13. Nalaskowski, F. Indoor education in Poland during the Covid-19. In Proceedings of the DIALOGO-CONF 2020, Constanta, Romania, 3-12 November 2020; Volume 6, pp. 57-62.

14. Parczewska, T. Difficult situations and ways of coping with them in the experiences of parents homeschooling their children during the COVID-19 pandemic in Poland. Educ. 3-13 2020, 1-12. [CrossRef]

15. Debowska, A.; Horeczy, B.; Boduszek, D.; Dolinski, D. A repeated cross-sectional survey assessing university students' stress, depression, anxiety, and suicidality in the early stages of the COVID-19 pandemic in Poland. Psychol. Med. 2020, 1-4. [CrossRef]

16. Rizun, M.; Strzelecki, A. Students' acceptance of the COVID-19 impact on shifting higher education to distance learning in Poland. Int. J. Environ. Res. Public Health 2020, 17, 6468. [CrossRef]

17. Crawford, J.; Butler-Henderson, K.; Rudolph, J.; Malkawi, B.; Glowatz, M.; Burton, R.; Magni, P.A.; Lam, S. COVID-19: 20 countries' higher education intra-period digital pedagogy responses. J. Appl. Learn. Teach. 2020, 3, 9-28. [CrossRef]

18. Aristovnik, A.; Keržič, D.; Ravšelj, D.; Tomaževič, N.; Umek, L. Impacts of the COVID-19 pandemic on life of higher education students: A global perspective. Sustainability 2020, 12, 8438. [CrossRef]

19. Wu, S.-J.; Chang, D.-F.; Sun, F.-R. Exploring college student's perspectives on global mobility during the COVID-19 pandemic recovery. Educ. Sci. 2020, 10, 218. [CrossRef]

20. Tanveer, M.; Bhaumik, A.; Hassan, S.; Ul Haq, I. Covid-19 pandemic, outbreak educational sector and students online learning in Saudi Arabia. J. Entrep. Educ. 2020, 23, 23.

21. Mok, K.H.; Xiong, W.; Ke, G.; Cheung, J.O.W. Impact of COVID-19 pandemic on international higher education and student mobility: Student perspectives from mainland China and Hong Kong. Int. J. Educ. Res. 2021, 105, 101718. [CrossRef] 
22. Young, S.; Young, H.; Cartwright, A. Does lecture format matter? Exploring student preferences in higher education. J. Perspect. Appl. Acad. Pract. 2020, 8, 30-40. [CrossRef]

23. Barada, V.; Doolan, K.; Burić, I.; Krolo, K.; Tonković, Ž. Student Life during the COVID-19 Pandemic Lockdown: Europe-Wide Insights. Available online: http://www.ehea.info/Upload/BFUG_DE_UK_73_11_6_students_Covid_19_survey_results.pdf (accessed on 5 December 2020).

24. Marek, M.W.; Chew, C.S.; Wu, W.V. Teacher experiences in converting classes to distance learning in the COVID-19 pandemic. Int. J. Distance Educ. Technol. 2021, 19, 89-109. [CrossRef]

25. Almazova, N.; Krylova, E.; Rubtsova, A.; Odinokaya, M. Challenges and opportunities for russian higher education amid COVID-19: Teachers' perspective. Educ. Sci. 2020, 10, 368. [CrossRef]

26. Nash, M.; Churchill, B. Caring during COVID-19: A gendered analysis of Australian university responses to managing remote working and caring responsibilities. Gender Work Organ. 2020, 27, 1-14. [CrossRef]

27. Kruszewska, A.; Nazaruk, S.; Szewczyk, K. Polish teachers of early education in the face of distance learning during the COVID-19 pandemic-The difficulties experienced and suggestions for the future. Educ. 3-13 2020, 1-12. [CrossRef]

28. Pérez-Jorge, D.; Rodríguez-Jiménez, M.d.C.; Ariño-Mateo, E.; Barragán-Medero, F. The effect of COVID-19 in university tutoring models. Sustainability 2020, 12, 8631. [CrossRef]

29. Gamage, K.A.A.; Pradeep, R.G.G.R.; Najdanovic-Visak, V.; Gunawardhana, N. Academic standards and quality assurance: The impact of COVID-19 on university degree programs. Sustainability 2020, 12, 10032. [CrossRef]

30. Bretag, T. Defining academic integrity: International perspectives-Introduction. In Handbook of Academic Integrity; Springer: Singapore, 2016; pp. 3-5.

31. 'Teddi' Fishman, T. Academic integrity as an educational concept, concern, and movement in US institutions of higher learning. In Handbook of Academic Integrity; Springer: Singapore, 2016; pp. 7-21.

32. König, J.; Jäger-Biela, D.J.; Glutsch, N. Adapting to online teaching during COVID-19 school closure: Teacher education and teacher competence effects among early career teachers in Germany. Eur. J. Teach. Educ. 2020, 43, 608-622. [CrossRef]

33. Oerther, D.B.; Peters, C.A. Think-Pair-Listen in the online COVID-19 classroom. Environ. Eng. Sci. 2020, 37, 647-648. [CrossRef]

34. Watermeyer, R.; Crick, T.; Knight, C.; Goodall, J. COVID-19 and digital disruption in UK universities: Afflictions and affordances of emergency online migration. High. Educ. 2020, 81, 1-19. [CrossRef]

35. Nuere, S.; de Miguel, L. The digital/technological connection with COVID-19: An unprecedented challenge in university teaching. Technol. Knowl. Learn. 2020. [CrossRef]

36. Hash, P.M. Remote learning in school bands during the COVID-19 shutdown. J. Res. Music Educ. 2021, 68, 381-397. [CrossRef]

37. Cervi, L.; Pérez Tornero, J.M.; Tejedor, S. The Challenge of Teaching Mobile Journalism through MOOCs: A Case Study. Sustainability 2020, 12, 5307. [CrossRef]

38. Cervi, L.; Simelio, N.; Tejedor Calvo, S. Analysis of Journalism and Communication Studies in Europe's Top Ranked Universities: Competencies, Aims and Courses. Journal. Pract. 2020, 1-21. [CrossRef]

39. Islam, M.A.; Barna, S.D.; Raihan, H.; Khan, M.N.A.; Hossain, M.T. Depression and anxiety among university students during the COVID-19 pandemic in Bangladesh: A web-based cross-sectional survey. PLoS ONE 2020, 15, e0238162. [CrossRef]

40. Asanov, I.; Flores, F.; McKenzie, D.; Mensmann, M.; Schulte, M. Remote-learning, time-use, and mental health of Ecuadorian high-school students during the COVID-19 quarantine. World Dev. 2021, 138, 105225. [CrossRef]

41. Gamage, K.A.A.; Wijesuriya, D.I.; Ekanayake, S.Y.; Rennie, A.E.W.; Lambert, C.G.; Gunawardhana, N. Online delivery of teaching and laboratory practices: Continuity of university programmes during COVID-19 pandemic. Educ. Sci. 2020, 10, 291. [CrossRef]

42. Raaper, R.; Brown, C. The Covid-19 pandemic and the dissolution of the university campus: Implications for student support practice. J. Prof. Cap. Community 2020, 5, 343-349. [CrossRef]

43. Olmos-Gómez, M.D.C. Sex and careers of university students in educational practices as factors of individual differences in learning environment and psychological factors during COVID-19. Int. J. Environ. Res. Public Health 2020, 17, 5036. [CrossRef] [PubMed]

44. Pasion, R.; Dias-Oliveira, E.; Camacho, A.; Morais, C.; Campos Franco, R. Impact of COVID-19 on undergraduate business students: A longitudinal study on academic motivation, engagement and attachment to university. Account. Res. J. 2020. ahead-of-print. [CrossRef]

45. Davis, F.D. A Technology Acceptance Model for Empirically Testing New End-User Information Systems: Theory and Results; Massachusetts Institute of Technology: Cambridge, MA, USA, 1986.

46. Masrom, M. Technology acceptance model and E-learning. In Proceedings of the 12th International Conference on Education, Bandar Seri Begawan, Brunei, 21-24 May 2007; pp. 21-24.

47. Abdullah, F.; Ward, R. Developing a general extended technology acceptance model for e-learning (GETAMEL) by analysing commonly used external factors. Comput. Hum. Behav. 2016, 56, 238-256. [CrossRef]

48. Lee, Y.-H.; Hsieh, Y.-C.; Chen, Y.-H. An investigation of employees' use of e-learning systems: Applying the technology acceptance model. Behav. Inf. Technol. 2013, 32, 173-189. [CrossRef]

49. De Smet, C.; Bourgonjon, J.; De Wever, B.; Schellens, T.; Valcke, M. Researching instructional use and the technology acceptation of learning management systems by secondary school teachers. Comput. Educ. 2012, 58, 688-696. [CrossRef]

50. Ching-Ter, C.; Hajiyev, J.; Su, C.R. Examining the students' behavioral intention to use e-learning in Azerbaijan? The general extended technology acceptance model for e-learning approach. Comput. Educ. 2017, 111, 128-143. [CrossRef] 
51. Agudo-Peregrina, Á.F.; Hernández-García, Á.; Pascual-Miguel, F.J. Behavioral intention, use behavior and the acceptance of electronic learning systems: Differences between higher education and lifelong learning. Comput. Hum. Behav. 2014, 34, 301-314. [CrossRef]

52. Venkatesh, V.; Davis, F.D. A theoretical extension of the technology acceptance model: Four longitudinal field studies. Manag. Sci. 2000, 46, 186-204. [CrossRef]

53. Hanif, A.; Jamal, F.Q.; Imran, M. Extending the technology acceptance model for use of e-learning systems by digital learners. IEEE Access 2018, 6, 73395-73404. [CrossRef]

54. Al-Gahtani, S.S. Empirical investigation of e-learning acceptance and assimilation: A structural equation model. Appl. Comput. Inform. 2016, 12, 27-50. [CrossRef]

55. Praveena, K.; Thomas, S. Continuance intention to use facebook: A study of perceived enjoyment and TAM. Bonfring Int. J. Ind. Eng. Manag. Sci. 2014, 4, 24-29. [CrossRef]

56. Abdullah, F.; Ward, R.; Ahmed, E. Investigating the influence of the most commonly used external variables of TAM on students' Perceived Ease of Use (PEOU) and Perceived Usefulness (PU) of e-portfolios. Comput. Hum. Behav. 2016, 63, 75-90. [CrossRef]

57. Hajiyev, J. Assessing students' attitude and intention to use $\mathrm{m}$ - learning in higher education. J. Contemp. Educ. Res. 2018, 2. [CrossRef]

58. Downey, J.P.; Kher, H. A longitudinal examination of the effects of computer self-efficacy growth on performance during technology training. J. Inf. Technol. Educ. Res. 2015, 14, 91-111. [CrossRef]

59. Liu, S.H.; Liao, H.L.; Pratt, J.A. Impact of media richness and flow on e-learning technology acceptance. Comput. Educ. 2009, 52, 599-607. [CrossRef]

60. Esteban-Millat, I.; Martínez-López, F.J.; Pujol-Jover, M.; Gázquez-Abad, J.C.; Alegret, A. An extension of the technology acceptance model for online learning environments. Interact. Learn. Environ. 2018, 26, 895-910. [CrossRef]

61. Salloum, S.A.; Qasim Mohammad Alhamad, A.; Al-Emran, M.; Abdel Monem, A.; Shaalan, K. Exploring students' acceptance of e-learning through the development of a comprehensive technology acceptance model. IEEE Access 2019, 7, 128445-128462. [CrossRef]

62. Sarstedt, M.; Ringle, C.M.; Hair, J.F. Partial Least Squares Structural Equation Modeling. In Handbook of Market Research; Springer International Publishing: Cham, Switzerland, 2017; pp. 1-40. ISBN 978-1-4522-1744-4.

63. Hair, J.F.; Hult, G.T.M.; Ringle, C.; Sarstedt, M. A Primer on Partial Least Squares StructuralEquation Modeling (PLS-SEM), 2nd ed.; SAGE Publications, Inc.: Thousand Oaks, CA, USA, 2017; ISBN 9781483377445.

64. Henseler, J.; Ringle, C.M.; Sarstedt, M. A new criterion for assessing discriminant validity in variance-based structural equation modeling. J. Acad. Mark. Sci. 2015, 43, 115-135. [CrossRef]

65. Ringle, C.M.; Wende, S.; Becker, J.-M. SmartPLS 3; SmartPLS: Bönningstedt, Germany, 2015.

66. Matthews, L. Applying Multigroup Analysis in PLS-SEM: A Step-by-Step Process. In Partial Least Squares Path Modeling; Springer International Publishing: Cham, Switzerland, 2017; pp. 219-243. ISBN 9783319640693.

67. Chen, T.; Peng, L.; Yin, X.; Rong, J.; Yang, J.; Cong, G. Analysis of user satisfaction with online education platforms in China during the COVID-19 pandemic. Healthcare 2020, 8, 200. [CrossRef] [PubMed]

68. Adedoyin, O.B.; Soykan, E. Covid-19 pandemic and online learning: The challenges and opportunities. Interact. Learn. Environ. 2020, 1-13. [CrossRef]

69. Almaiah, M.A.; Al-Khasawneh, A.; Althunibat, A. Exploring the critical challenges and factors influencing the E-learning system usage during COVID-19 pandemic. Educ. Inf. Technol. 2020, 25, 5261-5280. [CrossRef] [PubMed]

70. Patricia Aguilera-Hermida, A. College students' use and acceptance of emergency online learning due to COVID-19. Int. J. Educ. Res. Open 2020, 1, 100011. [CrossRef]

71. Siron, Y.; Wibowo, A.; Narmaditya, B.S. Factors affecting the adoption of e-learning in Indonesia: Lesson from Covid-19. J. Technol. Sci. Educ. 2020, 10, 282. [CrossRef]

72. Bhagat, S.; Kim, D.J. Higher education amidst COVID-19: Challenges and silver lining. Inf. Syst. Manag. 2020, 37, 366-371. [CrossRef]

73. Alqahtani, A.Y.; Rajkhan, A.A. E-learning critical success factors during the COVID-19 pandemic: A comprehensive analysis of e-learning managerial perspectives. Educ. Sci. 2020, 10, 216. [CrossRef] 